\title{
Application of the mineral liberation analysis (MLA) for extraction of grain size and shape measurements in siliciclastic sedimentary rocks
}

\author{
Joanna Pszonka ${ }^{1, *}$, Dariusz Sala ${ }^{2}$ \\ ${ }^{1}$ Polish Academy of Sciences, Mineral and Energy Economy Research Institute, Cracow, Poland \\ ${ }^{2}$ Polish Academy of Sciences, Institute of Geological Sciences, Krakow Research Center, Cracow, \\ Poland
}

\begin{abstract}
The mineral liberation analysis setup (MLA) consists of a scanning electron microscope (SEM) - based backscattered electron (BSE) image with an energy dispersive X-ray system (EDX) for elemental analysis and a computer software that integrates images and X-ray identification of minerals and maps their distribution. Thereby, various quantitative and qualitative data sets are collected including grain size distribution and shape parameters such as aspect ratio, shape factor and angularity. Other techniques, e.g. the Gazzi-Dickinson point counting method or frequently questionable image analysis software to extract data for textural analysis are time consuming, strenuous and with limitations that need to be addressed. Significant productivity of the mineral liberation analysis provides statistical representation and thereby stringent arguments to detect and suggest some potential solving in uncertainty and complexity of the submarine gravity flows phenomenon that is extremely difficult to monitor, however volumetrically the most significant processes moving sediments on Earth. The mineral liberation analysis seems to be one of the most suitable method to acquire such data set.
\end{abstract}

Keywords: scanning electron microscope (SEM), mineral liberation analysis (MLA), grain size distribution, textural parameters

\section{Introduction}

The mineral liberation analysis (MLA) is done by an automated measurement system, created to provide quantitative analyses of mineral species and material fragments. This system is based on a scanning electron microscope (SEM) with an energy dispersive X-ray (EDX) spectrometer and a software:

1. backscattered electron (BSE) image analysis allows to determine grain boundaries and sites for X-ray spectral acquisition,

2. X-ray spectra allow to classify samples by comparison to a library of reference spectra,

\footnotetext{
*Corresponding author: jpszonka@min-pan.krakow.pl
} 
3. software automates microscope operations and data acquisition.

The main advantages of using the MLA system are:

1. systematic, computer-automated and unattended operations reducing human errors and bias, and tedious manual analyses,

2. analysis of multiple samples increasing productivity and providing statistical representation,

3. cost effective,

4. ability to analyse very fine material at the scale of micrometres.

The main MLA-disadvantage is problematic distinguishing samples with similar compositions and polymorphs.

Creation and development of the MLA system was focused on applied mineralogy and metallurgical processes [1], such as ore body evaluation, geological exploration, geometallurgical mapping. However, the MLA-application has been extended for other studies including sedimentology $[2,3,4,5]$. The aim of this paper is to display how to obtain size- and shape-grain parameters of submarine gravity flow sediments. These textural characteristics are important indicators for submarine flow hydrodynamics.

\section{Material and Methods}

\subsection{Material}

The Cergowa sandstones from the Dukla and Fore-Dukla Units in the Outer Carpathians were deposited by high-density turbidites and hyperpycnal flows fed from a directly connected delta in the proximal part of the basin, and surge-type turbidity currents in the more distal localities $[6,7]$. These sandstones are fine- and very fine-grained and represent lithic wackes and arenites [8].

10 samples of the Cergowa sandstones were crushed to the gravel size in the Retsch Jaw Crusher BB 200, sieved to extract fraction $<315 \mu \mathrm{m}$ and ferromagnetic minerals were removed by a neodymium hand magnet. Further removal of ferromagnetic fraction was carried out using the Carpco MIH-13-111-5 and next the Frantz LB-1 magnetic separator. Subsequently the non-magnetic fraction was subjected to a heavy liquid separation by the tetrabromoethane (density of $2.97 \mathrm{~g} / \mathrm{cm}^{3}$ ) and the methylene iodide (density of $3.32 \mathrm{~g} / \mathrm{cm}^{3}$ ). The separation allowed to segregate light and heavy minerals. In this experiment heavy minerals were chosen for further proceeding and homogenized. Then, separated and homogenized minerals for each sample were prepared as standard petrographic thin sections, coated with carbon and labelled as 1-10CS.

\subsection{Methods}

The SEM generates a beam of incident electrons in a vacuum that is formed by a series of electromagnetic lenses separated by apertures in an electron column. The energy of incident electrons can be as high as $30 \mathrm{keV}$. Incident electrons react with the sample and produce three basic types of signals:

1. backscattered electrons (BSE) - high energy electrons that are ejected by an elastic collisions of incident electrons with nuclei of atoms in the sample and originated from a wide region within it; the energy of BSE is comparable to that of the incident electrons,

2. secondary electrons (SE) - lower energy electrons emitted by an inelastic interactions of incident electrons with valence electrons of atoms in the sample and 
scattering from a surface or a near surface region of the sample; the energy of SE is $50 \mathrm{eV}$ and less.

3. characteristic X-rays (EDX) - X-ray is emitted when the electron beam removes an inner shell electron and is replaced by an outer shell electron.

To create SEM images the electron beam is scanned in a raster pattern over a sample area, named a frame. Electrons are sensed for each position in the frame by electron detectors. BSE images provide information about distribution of elements, topography, crystallography and the magnetic field of samples. SE imaging can produce a very high resolution image of a sample surface. The intensity of the emitted electron signal is displayed as brightness in images. The magnification of an image is controlled by size of the frame, thereby reducing size of the frame results in an increase in frame resolution. Otherwise incident electrons that interact with the sample generate characteristic X-rays with measured energy levels that identifies present elements.

The MLA software integrates BSE images and X-ray data to identify materials and maps their distribution in the scanned sample area and then moves the electron beam to the next frame where measurements are retaken. Two MLA measurement methods are the most common:

1. the extended BSE (XBSE) for particle mounts, where the single X-ray analysis is used for identification of minerals and the BSE imaging for discrimination of their boundaries,

2. the grain X-ray mapping (GXMAP) for thin sections, where detailed X-ray analysis on a grid pattern is used for both identification of minerals and discrimination of their boundaries because BSE imaging is insufficient to distinguish them.

The backscattering coefficient is the ratio of the number of electrons backscattered by a mineral to the number of incident electrons from the SEM and is a function of the atomic number $\mathrm{Z}$ of the mineral. Minerals composed of lighter elements backscatter fewer electrons and appear darker in images, whereas minerals composed of heavier elements backscatter more electrons and appear brighter. The MLA system receives BSE data as a 256 greyscale image, from 0 that is black to 255 that is white, and relates the backscattering coefficient to the greyscale value. These greyscale variations provide distinguishing boundaries between minerals by the image separation function. It outlines regions with more or less homogeneous grey level in a particle image. Each BSE grey value of every region is related to minerals with unique $Z$. However, in the case when minerals have similar or the same atomic number $\mathrm{Z}$ and grey level, it is impossible to distinguish them by BSE imaging alone and X-ray analysis is needed for mineral classification.

The X-ray analysis links the spectrum of energy peaks from an unknown mineral with a library of X-ray spectra for known reference minerals collected by the same instrument parameters, except the acquisition time. The MLA software collates the spectrum of the unknown mineral to each known reference considering peak position, peak shape and intensity ratio. The program MLA Image Processing verifies the BSE images and X-ray data. The analysis products false colour images, assigned to minerals and linked with BSE images and quantitative data. Subsequently the program MLA Dataview evaluates results for all particles/grains as tables, graphs and diagrams or exports them to the Microsoft Excel. Before an extraction data do the Dataview, the set can undergo clean-up processes such as: deagglomeration, particle removal, frame removal, touch-up and mineral grouping in order to obtain proper liberation results.

Mineral liberation analysis measurements were performed at the Geometallurgy Laboratory at the TU Bergakademie Freiberg, on the scanning electron microscope FEI Quanta 600 FEG equipped with the Bruker Quantax Dual X-Flash Detector 5010 and the MLA-software Suite 3.1.4 for automated data acquisition. The imaging was carried out in the backscattered electron (BSE) with following parameters: accelerating voltage of $15 \mathrm{keV}$, 
electron beam current of $10 \mu \mathrm{A}$, and working distance 12-14 mm. Thin sections were measured in the GXMAP method, where each X-ray analysis was made for $8 \mathrm{msec}$ with a step size of 10 pixels on a $1.5 \times 1.5 \mathrm{~mm}$ frame with resolution of $500 \times 500$.

\section{Results}

The data set obtained from the MLA analysis with GXMAP technique from 10 samples of the Cergowa sandstones after clean-up processes are extracted to database and depending on study aims examined, processed, presented and stored by the Dataview software. The aim of this experiment is to obtain textural characteristics of turbiditic sandstones: size and shape measurement of grains, necessary for the comparative study of textural differences, such as four moment measures (mean, standard deviation, skewness, kurtosis), as well as supplemental median value. All values are here calculated with respect to grain's digital image (Fig. 1) with a basic measurement of shape:

1. particle/grain polygon - is determined from the boundary pixels of each shape,

2. convex hull polygon - is determined using the particle/grain polygon,

3. minimum bounding rectangle (MBR) is determined by finding the maximum vector onto which the projection width of the polygon points is at its maximum; then using the vector at $90^{\circ}$ to get the projection width for the other dimension for the minimum bounding rectangle.

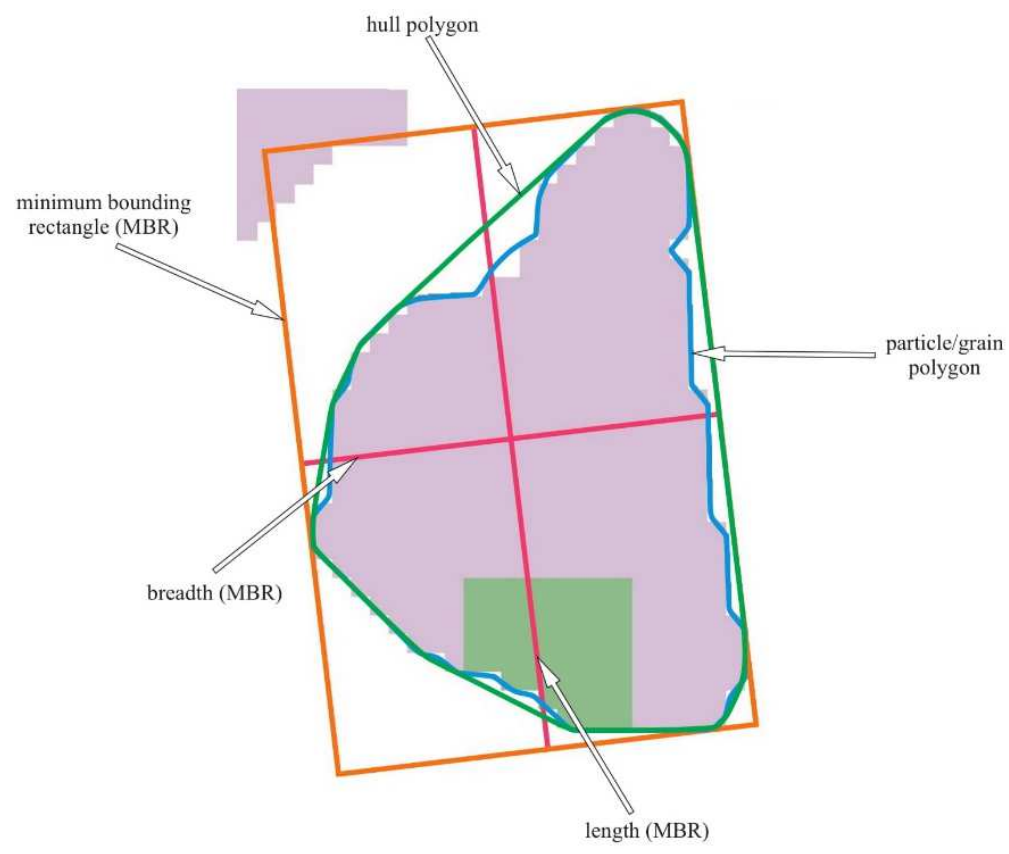

Fig. 1. Digital image of an exemplary particle made in GXMAP mode, with shape (particle/grain polygon, convex hull polygon, minimum bounding rectangle) and size (length and breadth MBR) measurements of particle.

Fig. 2 presents exemplary MLA results processed by the Dataview software for the sample 1CS, where following size measurements of grains are collected:

1. area - the area of the particle/grain in micron squared $\left(\mu \mathrm{m}^{2}\right)$,

2. perimeter - the surface perimeter of the polygon perimeter $(\mu \mathrm{m})$,

3. max span - the diameter of the minimum bounding circle $(\mu \mathrm{m})$,

4. length (MBR) - the length of the minimum bounding rectangle $(\mu \mathrm{m})$, 
5. breadth (MBR) - the breadth of the minimum bounding rectangle $(\mu \mathrm{m})$,

6. diameter - the equivalent circle (EC)diameter based on polygon area $(\mu \mathrm{m})$, in order to compute the shape calculations [3]:

7. aspect ratio $(\mathrm{AR})=\mathrm{LMBR} / \mathrm{BMBR}$, where $\mathrm{LMBR}$ and $\mathrm{BMBR}$ are the length and breadth of the minimum bounding rectangle of the particle/grain,

8. angularity $(\mathrm{ANG})=\Sigma\left(\mathrm{R}_{\mathrm{P}}-\mathrm{R}_{\mathrm{EE}}\right)^{2} /\left(\mathrm{REE}_{\mathrm{EE}}\right)^{2}$, where $\mathrm{RP}_{\mathrm{P}}$ is the radius of the particle measured from its geometric center and $\mathrm{REE}_{\mathrm{E}}$ is the radius of an equivalent area ellipse,

9. shape factor $(\mathrm{SF})=\mathrm{P} /[2 \pi \sqrt{ }(\mathrm{A} / \pi)]$, where $\mathrm{P}$ and $\mathrm{A}$ are the surface perimeter and area of the particle.

Thereby for the sample 1CS obtained 118012 results, for the sample $2 \mathrm{CS}-77605$, the $3 \mathrm{CS}-75328$, the $4 \mathrm{CS}-71144$, the $5 \mathrm{CS}-273$, the $6 \mathrm{CS}-16861$, the $7 \mathrm{CS}-19093$, the $8 \mathrm{CS}$ - 1793, the 9CS - 15162 and for the sample 10CS - 16997. Statistical results viz: mean, median, standard deviation, skewness and kurtosis for all samples are summarized in the Table 1. Additionally, the difference in the number of results in each sample informs about possible divergence in the content of minerals with density $>2.97 \mathrm{~g} / \mathrm{cm}^{3}$.

The Dataview software offers many possibilities to compile and compare obtained results using tables, graphs and diagrams, that facilitate imaging and interpretation of sediment flow dynamics. As an example, in the Fig 3 is presented a comparison of automatically generated grain size distributions of quartz grains (those with density $>2.97 \mathrm{~g} / \mathrm{cm}^{3}$ ) for all analyzed samples 1-10CS.

Table 1. Statistical results (mean, median, standard deviation, skewness, kurtosis) for 10 samples of the Cergowa sandstones (1-10CS) for indicated textural parameters (area, perimeter, max span, length, breadth, diameter).

\begin{tabular}{|c|c|c|c|c|c|c|}
\hline $\begin{array}{c}\text { PARAMETERS } \rightarrow \\
\text { DESCRIPTIVE } \\
\text { STATISTICS } \downarrow\end{array}$ & $\begin{array}{l}\text { Area } \\
{\left[\mu \mathrm{m}^{2}\right]}\end{array}$ & $\begin{array}{c}\text { Perimeter } \\
{[\mu \mathrm{m}]}\end{array}$ & $\begin{array}{c}\text { Max span } \\
{[\mu \mathrm{m}]}\end{array}$ & $\begin{array}{c}\text { Length } \\
\text { (MBR) } \\
{[\mu \mathrm{m}]}\end{array}$ & $\begin{array}{c}\text { Breadth } \\
\text { (MBR) } \\
{[\mu \mathrm{m}]}\end{array}$ & $\begin{array}{c}\text { Diameter } \\
{[\mu \mathrm{m}]}\end{array}$ \\
\hline \multicolumn{7}{|c|}{ Sample $1 \mathrm{CS}=118012$ results } \\
\hline Mean & 1964.88 & 209.83 & 55.61 & 56.56 & 36.32 & 41.08 \\
\hline Median & 1025.93 & 173.99 & 47.87 & 48.93 & 30.93 & 36.14 \\
\hline $\begin{array}{l}\text { Standard } \\
\text { deviation }\end{array}$ & 2953.29 & 173.73 & 42.02 & 41.21 & 27.05 & 28.54 \\
\hline Skewness & 4.23 & 2.14 & 1.38 & 1.38 & 1.49 & 1.40 \\
\hline Kurtosis & 31.78 & 8.61 & 2.91 & 2.93 & 3.40 & 2.96 \\
\hline \multicolumn{7}{|c|}{ Sample $2 \mathrm{CS}=77605$ results } \\
\hline Mean & 2872.11 & 251.85 & 64.02 & 64.56 & 41.42 & 46.07 \\
\hline Median & 1007.93 & 173.99 & 48.05 & 48.83 & 30.51 & 35.82 \\
\hline $\begin{array}{l}\text { Standard } \\
\text { deviation }\end{array}$ & 5320.66 & 254.84 & 57.62 & 56.35 & 37.42 & 39.17 \\
\hline Skewness & 4.13 & 2.27 & 1.58 & 1.58 & 1.79 & 1.75 \\
\hline Kurtosis & 24.79 & 7.80 & 2.87 & 2.90 & 3.88 & 3.72 \\
\hline \multicolumn{7}{|c|}{ Sample $3 C S=75328$ results } \\
\hline Mean & 2427.16 & 229.61 & 60.02 & 60.66 & 38.11 & 43.05 \\
\hline Median & 962.94 & 161.99 & 45.45 & 47.38 & 29.19 & 35.01 \\
\hline $\begin{array}{c}\text { Standard } \\
\text { deviation }\end{array}$ & 4608.07 & 232.85 & 53.77 & 52.74 & 33.32 & 35.17 \\
\hline Skewness & 5.10 & 2.78 & 1.87 & 1.88 & 2.02 & 1.92 \\
\hline Kurtosis & 44.67 & 12.91 & 5.03 & 5.13 & 5.63 & 5.11 \\
\hline \multicolumn{7}{|c|}{ Sample 4CS $=71144$ results } \\
\hline Mean & 2856.19 & 263.02 & 66.14 & 66.70 & 42.51 & 47.05 \\
\hline
\end{tabular}




\begin{tabular}{|c|c|c|c|c|c|c|}
\hline Median & 1115.93 & 191.99 & 52.08 & 53.52 & 33.00 & 37.69 \\
\hline $\begin{array}{l}\text { Standard } \\
\text { deviation }\end{array}$ & 4889.90 & 254.54 & 56.67 & 55.42 & 36.31 & 37.72 \\
\hline Skewness & 3.79 & 2.17 & 1.46 & 1.46 & 1.67 & 1.59 \\
\hline Kurtosis & 20.53 & 7.03 & 2.38 & 2.40 & 3.37 & 2.99 \\
\hline \multicolumn{7}{|c|}{ Sample 5CS $=273$ results } \\
\hline Mean & 2602.28 & 240.85 & 65.25 & 66.10 & 42.66 & 48.22 \\
\hline Median & 1502.90 & 215.99 & 59.01 & 60.22 & 38.24 & 43.74 \\
\hline $\begin{array}{l}\text { Standard } \\
\text { deviation }\end{array}$ & 3314.95 & 171.08 & 43.62 & 42.80 & 29.89 & 31.49 \\
\hline Skewness & 2.63 & 1.12 & 0.72 & 0.68 & 1.13 & 0.96 \\
\hline Kurtosis & 9.03 & 1.66 & 0.30 & 0.17 & 1.70 & 0.98 \\
\hline \multicolumn{7}{|c|}{ Sample $6 C S=16861$ results } \\
\hline Mean & 3159.60 & 263.14 & 74.86 & 75.42 & 49.79 & 58.39 \\
\hline Median & 2816.81 & 269.99 & 76.30 & 76.67 & 50.78 & 59.89 \\
\hline $\begin{array}{l}\text { Standard } \\
\text { deviation }\end{array}$ & 2389.38 & 116.09 & 33.13 & 32.59 & 22.72 & 24.76 \\
\hline Skewness & 2.00 & 0.43 & 0.11 & 0.13 & 0.09 & -0.03 \\
\hline Kurtosis & 11.24 & 4.67 & 1.18 & 1.25 & 0.59 & 0.64 \\
\hline \multicolumn{7}{|c|}{ Sample 7CS $=19093$ results } \\
\hline Mean & 2804.76 & 235.58 & 66.96 & 67.69 & 44.18 & 52.25 \\
\hline Median & 2195.85 & 233.99 & 66.51 & 66.85 & 44.92 & 52.88 \\
\hline $\begin{array}{l}\text { Standard } \\
\text { deviation }\end{array}$ & 3269.54 & 140.37 & 40.99 & 40.26 & 25.57 & 29.01 \\
\hline Skewness & 5.53 & 1.59 & 1.63 & 1.65 & 0.67 & 0.84 \\
\hline Kurtosis & 63.19 & 9.84 & 9.40 & 9.65 & 2.17 & 3.43 \\
\hline \multicolumn{7}{|c|}{ Sample $8 \mathrm{CS}=1793$ results } \\
\hline Mean & 2185.37 & 214.90 & 59.02 & 59.94 & 39.96 & 46.38 \\
\hline Median & 1709.89 & 209.99 & 58.70 & 60.00 & 40.40 & 46.66 \\
\hline $\begin{array}{l}\text { Standard } \\
\text { deviation }\end{array}$ & 2595.68 & 130.46 & 34.51 & 33.96 & 22.81 & 25.14 \\
\hline Skewness & 10.29 & 1.57 & 1.17 & 1.14 & 0.60 & 0.85 \\
\hline Kurtosis & 231.70 & 9.00 & 8.41 & 7.86 & 1.75 & 5.47 \\
\hline \multicolumn{7}{|c|}{ Sample $9 \mathrm{CS}=15162$ results } \\
\hline Mean & 4527.05 & 305.69 & 86.42 & 86.42 & 57.41 & 66.79 \\
\hline Median & 3730.25 & 311.99 & 89.09 & 88.47 & 58.37 & 68.92 \\
\hline $\begin{array}{l}\text { Standard } \\
\text { deviation }\end{array}$ & 4161.76 & 167.44 & 47.12 & 46.09 & 32.90 & 36.09 \\
\hline Skewness & 1.54 & 0.24 & 0.16 & 0.18 & 0.26 & 0.17 \\
\hline Kurtosis & 3.98 & 0.06 & -0.13 & -0.07 & -0.30 & -0.38 \\
\hline \multicolumn{7}{|c|}{ Sample 10CS $=16997$ results } \\
\hline Mean & 3147.48 & 261.95 & 74.56 & 75.08 & 49.70 & 58.24 \\
\hline Median & 2807.81 & 269.99 & 76.20 & 76.23 & 50.83 & 59.79 \\
\hline $\begin{array}{l}\text { Standard } \\
\text { deviation }\end{array}$ & 2373.16 & 115.40 & 33.07 & 32.51 & 22.79 & 24.82 \\
\hline Skewness & 1.95 & 0.27 & 0.04 & 0.07 & 0.07 & -0.06 \\
\hline Kurtosis & 11.35 & 2.79 & 0.79 & 0.87 & 0.59 & 0.56 \\
\hline
\end{tabular}




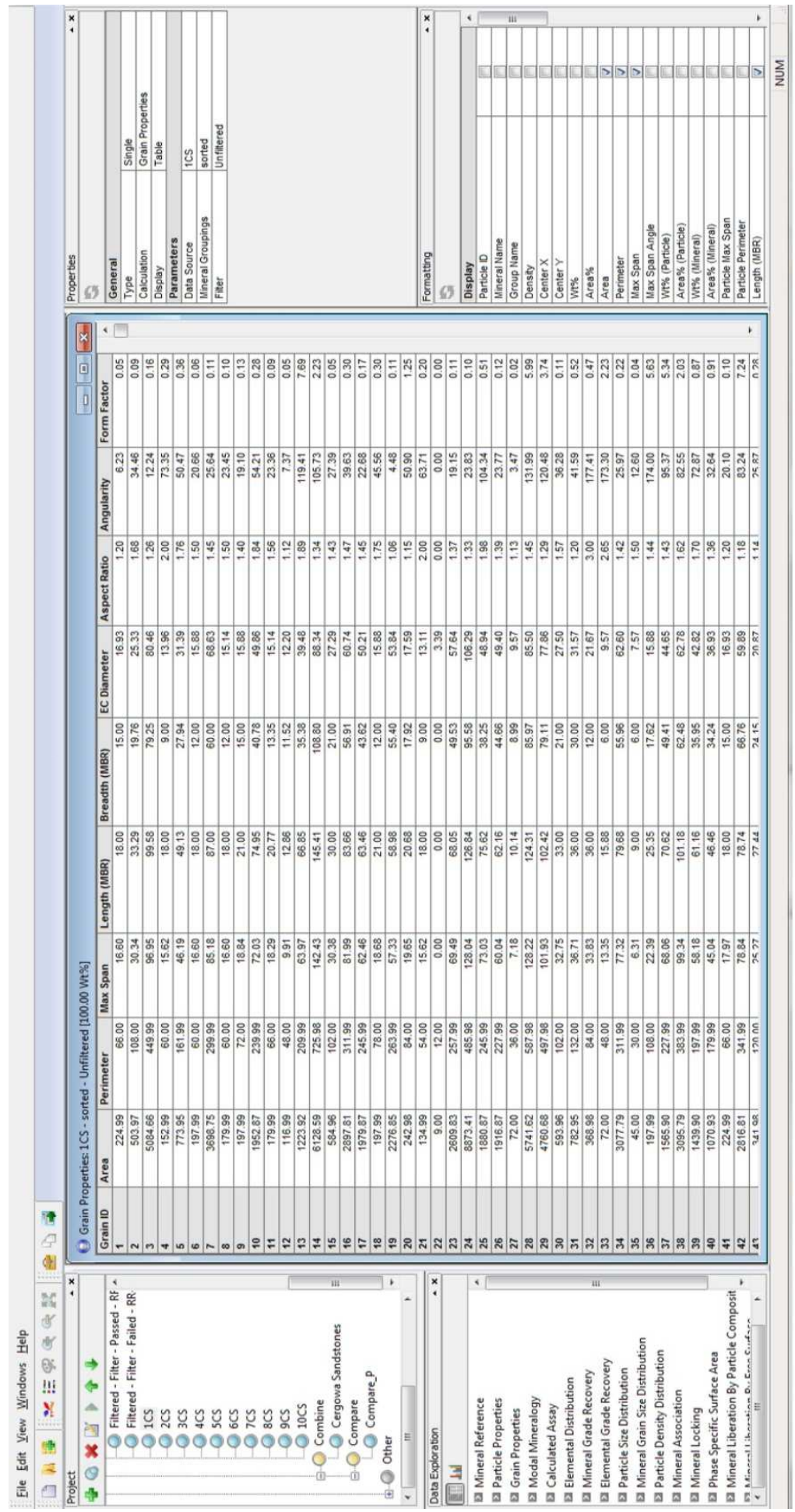

Fig. 2. The exemplary MLA results for the sample $1 \mathrm{CS}$ with the following size and shape measurements of grain: area, perimeter, max span, length (MBR), breadth (MBR), diameter, aspect ratio, angularity, form factor. 


\section{Mineral Grain Size Distribution}

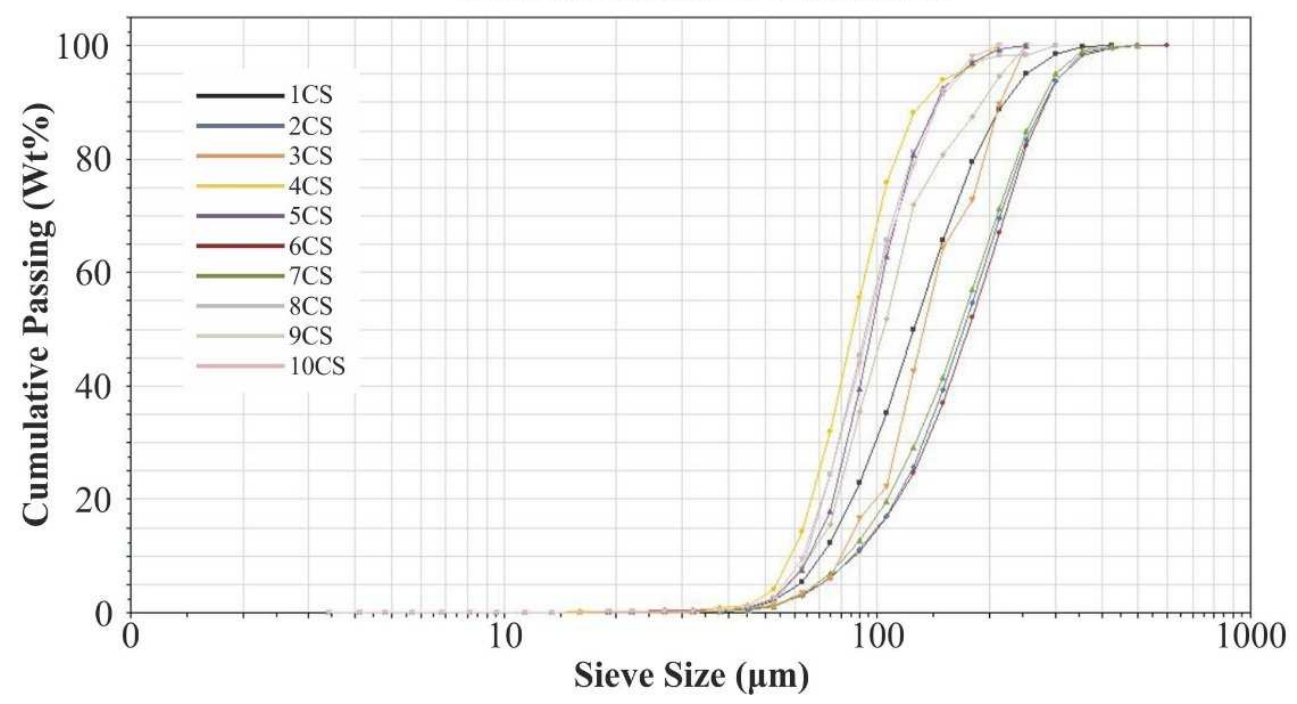

Fig. 3. Grain size distributions of quartz grains in samples 1-10CS.

\section{Discussion}

Textural characteristics of siliciclastic sediments are important indicators of flow hydrodynamics. Their differences shown by the size-shape sorting reflects depositional conditions. Sorting takes place over the entire distance travelled with the least transportable grains coming to rest first and the more transportable carried farther. The depositional sorting of grains is distinctly different for various sedimentary environments and even for various flow-regimes of transport in the same environment. Besides, a single flow-event may comprise several different flow types, and transformations can occur between these flow types. Understanding of sediment flow dynamics is considered as extremely complex, especially for enormously difficult to monitor submarine sediment flows.

Kneller and Buckee [9] underlined difficulties in understanding the dynamics of submarine suspended sediments and determined them immensely composite by virtue of turbulence. The phenomenon is non-linear, non-uniform (variation in space) and unsteady (variation in time). In addition, flow state, deposit type and flow transformation there are strongly dependent on the volume fraction of cohesive fine mud within a flow [10]. Their complexity expands even more with an increase of loads of cohesive sediments in suspension. However, in cases where mud content is volumetrically less significant, as in arenites, size and shape parameters of grains are crucial.

In this experiment, where the Cergowa sandstones represents mainly arenites [8], was shown the possibility of quick obtaining a huge amount of data, including statistical results, necessary for further analysis to define flow types and boundaries between them that form a continuum $[9,10]$. These data display both quantitative findings, such as size and shape measurements of grains, as well as qualitative findings, as a differentiation of mineral phases. The textural characteristics complete with sedimentary structures are significantly usable to interpret the last-stage evolution of density flows and depositional processes. Furthermore, textural properties next to mud content in deep water facies impact on the porosity and permeability distribution in a hydrocarbon reservoir, which are the most important petrographic parameters of any reservoir rocks, due to the ability to transmit and store fluids. 


\section{Conclusions}

On the basis of the study we can conclude:

1. The mineral liberation analysis is an automated measurement system that provides quantitative analysis, including size and shape measurements of grains in sedimentary rocks, such as: area, perimeter, max span, length (MBR), breadth (MBR), diameter, aspect ratio, angularity, form factor, necessary to determine depositional flow types and their transformations. Qualitative MLA-findings, such as mineral identification, complete these data.

2. The mineral liberation analysis seems to be one of the most suitable methods to extract data set for textural analysis in a large amount and relatively quick time.

3. The data set obtained from the mineral liberation analysis has great and strong potential to detect and suggest some solving in uncertainty and complexity of the difficult to monitor submarine gravity flows phenomenon because of large amount of data. Submarine gravity flows are especially noteworthy to track due to their importance in transporting sediments on Earth and industrial meaning.

This work was funded by the National Science Centre (NCN) Poland grant Miniatura 1 no. 2017/01/X/ST10/00048 for Joanna Pszonka. Acknowledgement to Professor Bernhard Schulz and Sabine Gilbricht for technical and reliable introduction to the MLA system.

\section{References}

1. R. Fandrich, Y. Gu, D. Burrows, K. Moeller, Int. J. Miner. Process. 84, 310-320 (2007) doi: 10.1016/j.minpro.2006.07.018

2. D.G. Lowe, P.J. Sylvester, M.E. Enachescu, AAPG Bull. 95, 1295-1320 (2011) doi: 10.1306/12081010005

3. V. Tsikouras, G. Pe-Piper, D.J.W. Piper, M. Shaffer, Sediment. Geol. 237, 150-165 (2011) doi: 10.1016/j.sedgeo.2011.02.011

4. M. Redwan, D. Rammlmair, J.A. Meima, Sci. Total Environ. 414, 480-493 (2012) doi: 10.1016/j.scitotenv.2011.10.038

5. H. von Eynatten, R. Tolosana-Delgado, V. Karius, K. Bachmann, L. Caracciolo, Sediment. Geol. 336, 68-80 (2016) doi: 10.1016/j.sedgeo.2015.10.008

6. P. Plink-Björklund, R.J. Steel, Sediment. Geol. 165, 29-52 (2004) doi: 10.1016/j.sedgeo.2003.10.013

7. J. Pszonka, Sedimentological study of the Cergowa Beds in the Dukla and Fore-Dukla Units of the Flysch Carpathians (in Polish, with English abstract) (Studia, Rozprawy, Monografie 196, IGSMiE PAN, Kraków, 2015)

8. J. Pszonka, J. Götze, J. Petrol. Sci. Eng. 161, 582-589 (2018) doi: 10.1016/j.petrol.2017.11.069

9. B.C. Kneller, C. Buckee, Sedimentology 47/s1, 62-94 (2000) doi: 10.1046/j.13653091.2000.047s1062.x

10. P.J. Talling, D.G. Masson, E.J. Sumner, G. Malgesini, Sedimentology 59, 1937-2003 (2012) doi: 10.1111/j.1365-3091.2012.01353.x 